ARTIGOS / ARTICLES

DOI: 10.5433/1679-0383.2021v42n1p147

\title{
Entre o deliberativo e o agonístico: algumas notas sobre democracia e feminismo em Mouffe e Benhabib
}

\section{Between the deliberative and the agonistic: some notes on democracy and feminism in Mouffe and Benhabib}

\author{
Rafael Marino ${ }^{1}$, Daniela Costanzo de Assis Pereira ${ }^{2}$
}

\section{Resumo}

\begin{abstract}
Pretendemos, com este trabalho, mostrar distinções importantes entre as compreensões que Chantal Mouffe e Seyla Benhabib teriam a respeito de questões como democracia, feminismo, poder, legitimidade, lutas democráticas e a constituição de sujeitos políticos. Sugerimos que estas diferenças estão vinculadas à compreensão agonística que Mouffe teria da política e da sociedade e à compreensão deliberativa de Benhabib sobre tais esferas. Com isto, não queremos esgotar o debate, mas, tão somente, levantar distinções importantes para pensarmos a produção de tais autoras. Tendo isso em vista, pretendemos lançar mão de alguns textos escritos por estas autoras de modo que possamos cumprir as seguintes etapas de trabalho: 1) mostrar alguns pressupostos teóricos que norteiam suas formulações; 2) mostrar alguns desenvolvimentos intelectuais destes pressupostos; 3) fazer uma breve comparação entre os argumentos destacados no ponto anterior na tentativa de indicar algumas conclusões.
\end{abstract}

Palavras-chave: Teoria política contemporânea. Teoria crítica contemporânea. Feminismo. Teorias democráticas. Teoria social contemporânea.

\begin{abstract}
In this paper, we want to show important distinctions between the understandings that Chantal Mouffe and Seyla Benhabib would have on issues such as democracy, feminism, power, legitimacy, democratic struggles and the constitution of political subjects. We suggest that these differences are linked to Mouffe's agonistic understanding of politics and society and Benhabib's deliberative understanding of such spheres. With this, we do not want to exhaust the debate, but only to raise important distinctions to think about the production of such authors. With this in mind, we intend to use some texts written by these authors so that we can fulfill the following work steps: 1) show some
\end{abstract}

\footnotetext{
${ }^{1}$ Doutorando em Ciência Política na Faculdade de Filosofia, Letras e Ciências Humanas da Universidade de São Paulo (FFLCH-USP), São Paulo, São Paulo, Brasil. Técnico de Programação Cultural no Serviço Social do Comércio (Sesc), São Paulo, São Paulo, Brasil. E-mail: rafael.marino50@gmail.com

${ }^{2}$ Doutoranda em Ciência Política na Faculdade de Filosofia, Letras e Ciências Humanas da Universidade de São Paulo, São Paulo, São Paulo, Brasil. Pesquisadora no Centro Brasileiro de Análise e Planejamento (Cebrap), São Paulo, São Paulo, Brasil.E-mail: danicosper@gmail.com
} 
theoretical assumptions that guide their formulations; 2) show some intellectual developments of these assumptions; 3 ) make a brief comparison between the arguments highlighted in the previous point in an attempt to indicate some conclusions.

Keywords: Contemporary political theory. Contemporany critical theory. Feminism. Democratic theories. Contemporary social theory.

\section{Apresentação geral}

O objetivo deste artigo é esquadrinhar diferenças e similitudes entre Chantal Mouffe e Seyla Benhabib no que diz respeito a suas compreensões de democracia, feminismo, poder, legitimidade, lutas democráticas e a constituição de sujeitos políticos. Para isso, serão levantados os pressupostos teórico-metodológicos de cada autora, bem como apresentados seus contrapontos práticos e discursivos.

Sugerimos que estas diferenças estão vinculadas à compreensão agonística que Mouffe teria da política e da sociedade e à compreensão deliberativa de Benhabib sobre tais esferas. De forma sucinta, para Mouffe, o político seria essencialmente pautado por disputas entre grupos e identidades políticas e sociais diversas, isto é, o cerne agonístico da esfera do político é irredutível e lhe é característico. Desta forma, a existência de grandes consensos prévios e morais os quais circunscreveriam o que seria moralmente razoável na sociedade e na política seriam ideológicos e acabariam por expulsar as discordâncias e o pluralismo de valores da democracia. Benhabib, por sua vez, pensaria em termos de uma democracia deliberativa e procedimentalista como uma forma de abarcar razoavelmente o pluralismo de valores da sociedade - os quais poderiam ser conflitantes entre si, mas não poderiam se anular-, que seriam filtrados por procedimentações democráticas moralmente legítimas.

A fim de demonstrar a nossa hipótese de leitura, passaremos em revista alguns pressupostos e argumentações de Mouffe e de Benhabib.

\section{Alguns pressupostos do agonismo de Mouffe e do deliberativo em Benhabib}

\section{Hegemonia, sujeitos politicos e agonismo em Mouffe}

Começando por Mouffe, é interessante que indiquemos alguns deslocamentos efetuados pela autora em sua carreira, tanto em relação ao debate da esquerda, de modo geral, quanto ao do feminismo em particular. Desta feita, o ponto de partida que aqui se faz necessário é o conjunto de reflexões por ela efetuada em parceria com Ernesto Laclau, presentes no livro Hegemonia e estratégia socialista: por uma política democrática radical. Porém, para que o debate ali gestado ganhe a concretude e a dimensão histórica merecidas é preciso uma breve incursão nas lições de Marx e Engels (2009, 2010), que basearam, por diferentes vias, as teorias das autoras aqui tratadas.

A crítica praticada por Marx e Engels pretendia-se não externa e sim imanente ao objeto estudado, na qual, como gostaria $\mathrm{Hegel}^{3}$, tomaríamos o objeto nele mesmo, sem uma violência externa a ele, em que haveria a imputação de um padrão de medida exógeno à disciplina mesma da coisa estudada ${ }^{4}$ - mesmo que todo esse processo exija o mais extremo esforço do conceito. A questão fica clara se pensarmos na famosa crítica à ideologia, a qual não pode ser confundida com a sua vulgata, que tornaria a crítica uma mera acusação abstrata e generalizada da pretensa falsidade da totalidade do 'mundo burguês'. Uma vez que, para os nossos autores, há sempre um movimento de verdade na

3 "O exame não é só um exame do saber, mas também de seu padrão de medida” (HEGEL, 2012, p. 80).

${ }^{4}$ Como dizia Adorno, demovendo a visão de que Hegel poderia cair em certo positivismo: "Hegel se curva em toda parte à essência própria do objeto, em toda parte o objeto é renovadamente imediato, mas mesmo essa subordinação à disciplina da coisa exige o mais extremo esforço do conceito" (ADORNO, 2013, p. 78). 
falsidade, o qual deve ser superado em sua 'unilateralidade'. Ou, em outras palavras, para ambos a ideologia burguesa ao descrever o mundo no diapasão da realização de trocas iguais e justas, o faz muito bem - à maneira de um Adam Smith ou um Ricardo -, porém não vê que por baixo dessa Aparência de igualdade, há uma Essência desigual. Desigualdade produzida a partir da 'utilização' da mercadoria força de trabalho, que ao plasmar a mercadoria pela via do trabalho humano, valoriza-a. Deste modo aquele quantum oferecido pela sua compra é sempre menor que o resultante do processo capitalista de trabalho - D - M - D', de acordo com a famosa fórmula de Marx. Nesse bojo, é preciso notar, com Adorno (2004, p. 427-447), que a ideologia é falsa não em suas promessas Liberdade, Igualdade, Emancipação e Autonomia, mas lá onde diz que estas já foram realizadas.

Já Mouffe e Laclau, no livro supracitado, irão promover um deslocamento importante dentro do debate sobre o marxismo, argumentando que o ideário supostamente jacobino de Marx e Engels - posteriormente herdado pelos bolcheviques ${ }^{5}$ - deveria ser substituído por uma ideia de democracia radical. Essa operação de deslocamento teria como pivô o conceito de Hegemonia, reaproveitado, como deixam claro, a partir dos Cadernos do Cárcere do marxista italiano Antonio Gramsci. Utilizo o termo reaproveitado e não emprestado, já que o conceito passa por uma transformação sensível com Mouffe e Laclau, pois apesar de o marxista sardo efetuar uma nacionalização do marxismo na Itália - reconhecendo a necessidade de se agir em uma realidade nacional concreta e levando a cabo uma fusão virtuosa entre teoria e prática, fugindo tanto de um localismo vulgar, quanto de um cosmopolitismo abstrato (RICUPERO, 2000, p. 61-92) - o horizonte revolucionário ainda galvaniza seu pensamento e ação (GRAMSCI, 2014a, p. 11-113; GRAMSCI, 2014b, p. 11-129).

Todavia, tanto os teóricos contemporâneos, quanto o comunista italiano teriam em comum a manutenção de uma dimensão essencial da hegemonia, qual seja: a de possibilitar o surgimento do que Mouffe e Laclau chamam de um 'novo sistema de equivalentes'. Para Gramsci, o bloco histórico de um povo-nação - entre operários, camponeses e outros grupos -, envolvendo, também, a unidade dialética entre forças produtivas, relações sociais de produção e superestrutura jurídico-política, teria a tarefa histórica de resolver os problemas nacionais italianos e forjar uma revolução socialista por lá. Já para Mouffe e Laclau, permitir-se-ia a constituição de um novo sistema de equivalentes dos oprimidos, em geral, contra a opressão e a continuidade da Revolução Democrática, cujo início data da Revolução Francesa de 1789.

Nesse sentido, apesar de semelhanças entre o conceito de hegemonia em Gramsci e o utilizado por Laclau e Mouffe, principalmente no que se refere à dimensão privilegiada conferida à articulação política e à ideologia, há diferenças importantes. Se Laclau e Mouffe falam sobre a criação de um sistema de equivalente entre os oprimidos, em Gramsci a articulação hegemônica deveria remeter a uma classe fundamental: o proletariado. Outro elemento decisivo, segundo Alves (2010, p. 94-95), é que “enquanto em Gramsci a hegemonia remete à unidade de todo bloco histórico, Laclau e Mouffe questionam todo tipo de sutura, pois consideram que isso seja impossível". Portanto, enquanto Gramsci acreditava ser possível a criação de uma sociedade sem classes e a construção do socialismo, nos quais a atividade política e o partido seriam obsoletos e desapareceriam, "para Laclau e Mouffe (2001) não há possibilidade de uma reconciliação final, uma vez que o antagonismo é constitutivo do social e que ele apresenta um caráter aberto e incompleto". Isso se daria, dentre outras coisas, porque Mouffe e Laclau avaliariam que o marxismo seria ainda caudatário de essencialismos de classe e determinismos de ordem econômica os quais o impediriam de se abrir completamente ao caráter radicalmente contingente e

\footnotetext{
5 Tendo uma formalização clara em: (LENIN, 2010).
} 
incompleto do social. Nesse sentido, a hegemonia, para os dois teóricos contemporâneos, passaria a ser entendida como uma operação política de constituição do social, na qual demandas e identidades particulares passariam a representar e dar voz a outras demandas e identidades particulares por meio da construção de um universal compartilhado. Isso tudo através de articulações políticas e ideológicas contingentes, por meio das quais são criadas fronteiras políticas novas - elas mesmas mutáveis e contingentes (LACLAU; MOUFFE, 2001).

Disto isto, a pesquisadora belga e o argentino operariam os seguintes deslocamentos: a) no lugar da centralidade do movimento dos trabalhadores, valorizariam algo próximo do que Arato e Cohen (1992, p. 1-26; 492-563) chamam de novos movimentos sociais, indicando a multiplicação do número de antagonismos, com novas disputas e novas formas de subordinação, abrindo espaço para a indeterminação quanto aos espaços possíveis de disputa política, antes indexados a pontos nodais essenciais e privilegiados para a mudança política; b) o ponto anterior anda de mãos dadas com a crítica de ambos à essencialização dos sujeitos e do próprio chamado sujeito revolucionário, até porque os sujeitos, seguindo as lições do pós-estruturalismo, seriam constituídos discursivamente e via poderes, inserindo-os em uma miríade de relações de antagonismo, opressão e subordinação; c) a partir dos pontos anteriores é possível notar que as bases para a concepção revolucionária-jacobina foram minadas, mostrando-se a impossibilidade desta promover uma racionalização/reorganização total da sociedade, perspectiva a qual, ao fim e ao cabo, seria incompatível com a pluralidade e abertura que uma democracia radical requer; d) as autoras enfatizam a necessidade de se fazer uma verdadeira guerra de posições, a fim de que haja a expansão de uma ideologia liberal-democrática, expandindo a luta democrática por toda a Sociedade Civil e para o Estado, em direção a uma democracia radical em que o socialismo, entendido como socialização e acesso democrático aos meios de produção por toda a sociedade, torna-se um de seus elementos e não o objetivo fulcral.

Antes de partir para o desvelamento de alguns pressupostos de Benhabib, é forçoso olhar com mais vagar para o segundo ponto anteriormente elencado e adentrar nele, até para que possamos entender adequadamente a concepção agonística de democracia, bem como suas relações com o feminismo. Mouffe, servindo-se de um arsenal forjado nas discussões pós-estruturalistas, critica uma noção de sujeito considerada por ela essencialista e deficitária do ponto de vista da construção de uma teoria alternativa democrática à situação presente. Essa crítica ao essencialismo possuía dois alvos: o primeiro é uma certa concepção de sujeito cuja imaginação o faz pensar como senhor de sua própria morada e que, utilizando-se de seu esclarecimento (KANT, 2011, p. 23-24), ousaria tentar dominar a alteridade e a natureza ao seu redor. Ou seja, um sujeito que agiria sob o signo de uma racionalização implacável - tanto interna ao indivíduo, quanto externa -, na qual expulsar-se-ia os afetos, os micropoderes em relação e os discursos em circulação, tão caros a Mouffe e sua noção de sujeito. Já o segundo alvo seriam algumas teóricas e militantes feministas, das mais diversas correntes, como a Carole Pateman, a psicóloga do desenvolvimento, Carol Gilligan e as chamadas maternalistas, Sara Ruddick e Jean Elshtain, as quais, ao fim e ao cabo, acabavam por essencializar atributos pretensamente exclusivos das mulheres, à maneira da maternidade e do cuidado, ou entificando a divisão homem/mulher na sociedade (MOUFFE, 2000, p. 101-121).

Essa crítica à entificação dos sujeitos $^{6}$, aproxima-se muito do que fora feito por uma teórica como Judith Butler (BUTLER, 2003), a qual, grosso modo, preocupa-se em desvelar os discursos, relações de poder e instituições engendradoras de identidades e sujeitos, como o conceito de 'mulher universal'. Formulação que até poderia

\footnotetext{
${ }^{6}$ Aqui há influência das reflexões de Derrida e Lacan bastante claras; para mais, ver: (DERRIDA, 1995, p. 11-53; p. 227-249); (LACAN, 1998, p. 96-104).
} 
se querer igualitária, mas, no final das contas, geraria uma exclusão/ocultação em relação aos que estariam fora daquela concepção de mulher - os chamados "abjetos", como diria Butler. Sendo assim, tanto ela quanto Mouffe lançariam mão de uma noção de autonomia e de possibilidade de transformação política diversas das de Benhabib, quiçá, diminutas, como veremos a seguir (CYFER, 2015). Isto é, Mouffe, desde seus escritos com Laclau, já teria chamado a atenção para o fato de que a noção de autonomia poderia ser enganosa, visto que deixaria de lado os inúmeros poderes e discursos que conformam os sujeitos e seus agenciamentos. Em certo sentido, poderíamos dizer que Mouffe, concordando com Foucault (2012) e Butler (1997), acreditaria que não há nada fora do poder.

\section{Teoria normativa, deliberacionismo e crítica em Benhabib}

A teórica turco-estadunidense Seyla Benhabib comumente é vinculada a uma corrente do feminismo a qual tenta combinar este movimento com os pressupostos e preocupação da chamada segunda geração da Teoria Crítica da Sociedade. Entretanto duas questões importantes vêm à mente com esta afirmação: i) como é possível uma teoria crítica desenvolvida fora da Alemanha e do famoso Institut für Sozialforschung? ii) como esses pressupostos afetam a teorização de tal autora sobre a democracia deliberativa e sobre o feminismo?

A assim chamada Teoria Crítica, apesar de sua forte identificação com o pensamento e o território alemão, país sede do Instituto acima citado ${ }^{7}-$ principalmente com filósofos e teóricos como Theodor W. Adorno, Max Horkheimer e Jünger Habermas - iria além desta identificação, pois, como queria Marcos Nobre: a teoria, quando forjada em um campo crítico, não deve se restringir à imediaticidade descritiva de como as coisas funcionam e sim "analisar o funcionamento delas à luz de uma emancipação ao mesmo tempo concretamente possivel e bloqueada pelas relações sociais vigentes" (NOBRE, 2004, p. 32). Em outras palavras, tendo em vista uma crítica imanente das relações sociais e materiais vigentes em um período histórico específico, vislumbrar-se-iam os potenciais emancipatórios encalacrados em seu bojo. Assim sendo, a teoria, a um só tempo, poderia dar conta da especificidade sócio-histórica de desenvolvimentos materiais e históricos específicos, sem deixar de dar conta de certa preocupação 'universalista' - cuja fundamentação deveria ser bastante concreta, como queria Benhabib e que exploraremos melhor adiante - inerentes às preocupações emancipatórias advindas desde os primórdios da tradição crítica, como na teorização do próprio Marx. E aqui uma pequena digressão histórica e teórica se faz benfazeja, a fim de que localizemos melhor o que fora dito até agora.

Horkheimer, em sua conferência inaugural como diretor do Instituto de Pesquisa Social, pretendia formular uma atualização do materialismo histórico de Marx, tendo por base um diagnóstico do presente histórico, referenciando-se nas mudanças históricas do capitalismo - à maneira dos escritos de Friedrich Pollock sobre a mudança de um Capitalismo Concorrencial para um Capitalismo Monopolista de Estado e o fato deste levar a uma repolitização das relações sociais, superando-se o mercado como alocador dos recursos em direção a uma reorganização planificada da economia, cujo fundamento é o controle político exercido diretamente por este mesmo Estado (POLLOCK, 1985, p. 71-95) (RUGITSKY, 2015, p. 53-73) e as mudanças políticas ocorridas na Alemanha com a ascensão vertiginosa dos votos no Partido Nacional Socialista dos Trabalhadores Alemães de Adolf Hitler. Nesse ínterim, Horkheimer não irá entender mais o materialismo como uma expressão teórica de um momento histórico e revolucionário - à maneira de um Marx e de um Lukács em História e Consciência de Classe -, mas sim como uma teoria social, da qual dever-se-ia

\footnotetext{
${ }^{7}$ Para mais sobre as reviravoltas da história de criação do Instituto até o período da chamada segunda geração, ver: (JAY, 2008).
} 
depreender uma crítica radical à situação dada e que permitisse uma disputa interna à filosofia e às ciências sociais.

Ainda nesse diapasão, é importante notar um deslocamento importante quanto ao marxismo e extremamente produtivo para a teorização posterior, qual seja: ao encarar o materialismo como uma teoria social, questionando a validade objetiva necessária do ponto de vista do proletariado, abre-se espaço para uma filosofia assentada no sofrimento e no ponto de vista dos indivíduos na sociedade sem que este sofrimento bárbaro fosse transfigurado em um momento necessário da civilidade (HORKHEIMER, 1999, p. 120-124). Deste modo, aponta-se para uma relação no mínimo tensa entre o proletariado - ou grupos oprimidos em geral, como ficará patente com o desenvolvimento posterior da teoria crítica - e a teorização crítica de autores e autoras pertencentes a esta tradição (HORKHEIMER, 1983, p. 48). Seguindo o argumento, com essa mudança do materialismo em direção a uma teoria social, este passaria de uma teoria do conflito de classe para uma teoria social que também daria conta do conflito de classes, contudo isto deve estar subordinado a um diagnóstico sobre a presente sociedade capitalista. Diagnóstico apenas tornado possível a partir do momento em que se repensasse a relação entre as demais ciências e a filosofia social, forjando-se o assim chamado materialismo interdisciplinar, em que ficaria patente o duplo caráter da ciência produzida pelos círculos mais avançados: entre a ideologia e força produtiva (HORKHEIMER, 1983, p. 35).

Porém, como havia sido dito na seção anterior, baseando-nos, principalmente, em A ideologia Alemã, toda ideologia teria um tanto de verdade embrenhada em si e seria papel de uma teoria crítica e de um sujeito dotado de uma postura crítica desentranharem da chamada teoria tradicional e de suas formulações científicas este momento de verdade. Momento de verdade mostrado a partir da etapa em que a/o teórica(o) crítica(o) demonstrasse a sua essência parcial, mesmo apresentando-se como total, além de histórica e socialmente situada - ou aparecendo como uma formulação autossuficiente, acabada e socialmente neutra. Desta feita, uma das tarefas essenciais da Teoria Crítica da Sociedade seria a de estabelecer uma relação de negação determinada e superação dialética com o conhecimento de ponta e tradicional produzido até o momento, ressaltando exatamente as diferenças entre o que havia de 'ilusório' e o que havia de produtivo neste, tudo isso visando uma sociedade emancipada, cujas potencialidades estavam inscritas nas relações sociais até então vigentes.

Esses lineamentos forjados por Horkheimer serão fundamentais para gerações posteriores de teóricos críticos (NOBRE, 2004; NOBRE, 2015, p. 9-21), como é o caso de Jünger Habermas e os desdobramentos efetuados em seus escritos ${ }^{8}$. Para o que nos interessa nesse trabalho, é preciso ver que o filósofo alemão, servindo-se das lições de Adorno e Horkheimer ${ }^{9}$, argumenta que, com os desdobramentos históricos da primeira metade do século XX e parte da segunda metade, poder-se-ia perceber, a olhos vistos, o esgotamento daquilo que chama de energias utópicas - conceito chave para a temporalidade moderna, na qual o presente é entendido como passagem para o novo, esperando-se do passado uma renovação contínua. Até porque, desde o século XIX, estas eram pautadas, de uma forma ou de outra, na expectativa de que com a técnica, a ciência e o planejamento racional haveria a consolidação de um controle racional e apaziguador da natureza e, por conseguinte, da sociedade. Todavia, o que se viu é que essas promessas deram, via de regra, no seu contrário: as técnicas levaram a consequências colaterais sérias e a capacidade

\footnotetext{
${ }^{8}$ É evidente que aqui não pretendemos lançar mão todas as viravoltas e mudanças do rico pensamento de Habermas e sim apenas aquilo que interessa aos nossos propósitos neste breve texto.

${ }^{9}$ Para uma visão - pouco exaustiva, é claro - do aproveitamento e das críticas efetuadas por Habermas, aos primeiros teóricos da assim chamada Teoria Crítica - mais precisamente, aos ecos e consequências do que chama de paradigma produtivista, que tem por cerne, grosso modo, uma visão da emancipação como superação do chamado trabalho heterônomo -, ver, principalmente: (HABERMAS, 2014; HABERMAS, 2012; MELO, 2013; NOBRE, 1998).
} 
de planejamento se interverteu em transtorno. À primeira vista, todas as utopias emancipatórias haviam chegado ao fim - como queria boa parte do pensamento pós-moderno - contudo, determinada utopia havia chego ao fim: a utopia cristalizada a partir das potencialidades da sociedade do trabalho, ou, para usar o jargão, o paradigma produtivista (HABERMAS, 2015, p. 207-218).

Seguindo Marx e até mesmo Weber, poderse-ia ver que a forma do trabalho abstrato "desdobrou uma tamanha força pregnante, penetrando todos os domínios, também as expectativas utópicas passaram a dirigir-se à esfera produtiva, em suma: a uma emancipação do trabalho em relação à determinação alheia" (HABERMAS, 2015, p. 215). A passagem do chamado trabalho heterônomo, para o trabalho autônomo, em suma. Contudo, esta mesma utopia perdeu o seu referente na realidade, já que, de acordo com alguns estudos de Claus Offe (apud HABERMAS, 2015, p. 217), a força formada e construtora de estruturas proveniente deste trabalho abstrato diminui drasticamente com a diminuição objetiva da força de determinação, remuneração e produção para a instituição e manutenção da sociedade - para além da perda de inocência das forças produtivas e do fato de a abolição da propriedade privada não ter cumprido o que prometia. Porém, é forçoso dizer que além de influenciar uma gama variada de intelectuais, o paradigma colocado acima acabou por influenciar demasiadamente o movimento operário no século XX e galvanizou três das principais respostas no pós-guerra: a) a Revolução Russa de 1917 e o movimento comunista; b) o corporativismo fascista da Itália e Alemanha; c) o reformismo socialdemocrata das democracias de massa ocidentais. Concentremo-nos no último caso.

Segundo o filósofo alemão, um programa em termos de um Estado de Bem-Estar Social para manter acessa as suas potencialidades voltadas para uma vida coletiva melhor e menos arriscada, deveria deixar de nutrir-se da utopia da sociedade do trabalho, visto que condições de vida humana dignas e emancipadas, já não tem a ver mais, de modo imediato, com um revolucionamento das condições de trabalho em direção à sua condição autônoma. É claro que dever-se-ia manter a reforma das relações de emprego, para que houvesse a humanização de um trabalho ainda heterônomo e operações compensatórias quanto ao risco do trabalho, com o intuito de dinamitar os potenciais conflitivos ligados ao status do trabalho assalariado. Tudo isso tendo em vista uma ação estatal democraticamente legitimada, objetivando elevar e domesticar o processo de crescimento capitalista naturalizado, sendo que a população, nesse ínterim, teria direitos políticos para tomar parte e direitos sociais de ter parte, com o objetivo de que as massas obtenham o direito de viver em liberdade, com justiça social e prosperidade crescente. Porém, Habermas vê dois problemas importantes nesse bojo: i) o compromisso em torno de tal Estado não é estruturalmente tão acentuado, levando a problemas de legitimidade e ii) a intervenção do Estado não se dava apenas na economia, mas sim no ciclo de vida de seus cidadãos.

Ao que o filósofo propõe, como alternativa, uma divisão complexa entre poderes, lembrando que as sociedades complexas giram em torno de três recursos principais: dinheiro, poder e solidariedade. De sorte que as esferas de influência destes deveriam ser colocadas em um novo equilíbrio, no qual a solidariedade se sobrepujasse contra o poder dos outros dois recursos; uma operação que deveria andar de mão dadas com a formação política da vontade, devendo influenciar no traçado dos limites e o intercâmbio entre esses âmbitos da vida comunicativamente estruturados, de um lado, e a economia e o Estado, de outro. Para tal, Habermas propõe uma estruturação sofisticada, pautada em três arenas distintas: a) arena em que as elites políticas levam a cabo suas decisões no aparelho estatal; b) arena em que um grande número de grupos anônimos e atores coletivos influenciam uns aos outros, forjar coalizões de modo a dominar os meios de produção e os meios de comunicação, definindo previamente o espaço de tematização e decisão de questões políticas; c) esta última é 
caracterizada por fluxos comunicativos dificilmente palpáveis e que conformam as formas de cultura política, e, com a ajuda de definições de realidade, se rivalizam em torno da chamada hegemonia cultural. Todavia, para colocar em prática o deslocamento de pesos em favor de operação solidária, esta terceira arena deve se sobrepor a outras duas, dado que é ali que ocorreram as disputas em torno de definições, não de poder ou dinheiro; defendendose estilos de vida e subculturas, com a transformação de formas de vida transmitidas.

Dito isto, é importante notar que Habermas tem em mente a entrada em cena dos chamados novos movimentos sociais - estruturalmente distintos do chamado movimento operário e sua atuação, até porque são marcados por reivindicações não 'materiais' e com uma concepção de ação política autolimitada (ARATO; COHEN, 1992, p. 1-26; 492-563); (AVRITZER, 1999, p. 167-188); (MELUCCI, 1985, p. 789-816) - ao modo do movimento ecologista e feminista (NOBRE, 2013, p. 17-18). Gerando uma situação histórica com dois tipos de delimitações importantes: i) uma positiva, em que os palcos anteriormente expostos poderiam se tornar esferas públicas autônomas que se comunicam entre si, com um grande potencial de autoorganização e o uso auto-organizado dos meios de comunicação, isso junto com uma autolimitação importante dos mecanismos de autocontrole do Estado e da economia perante a formação democrática da vontade; ii) outra negativa, em que o Estado de Bem-Estar deveria se tornar reflexivo e se despedido da utopia do trabalho, devendo-se, assim, deslocar os acentos utópicos para o conceito de comunicação.

Conceito cujo conteúdo utópico seria reduzido ao de uma intersubjetividade incólume, sendo assim, o que se distinguiria normativamente são as condições universais e necessárias, "para uma práxis comunicativa cotidiana e para um procedimento de formação discursiva da vontade que poderiam colocar os próprios participantes em condições de realizar, por iniciativa própria, as possibilidades concretas de uma vida melhor e menos arriscada, segundo as necessidades e os discernimentos próprios" (HABERMAS, 2015, p. 238) ${ }^{10}$. Coloca-se, assim, em circulação uma compreensão das lutas como essencialmente plurais, sem uma possibilidade de totalização - à maneira do antigo paradigma produtivista. Um deslocamento que

pressupõe processos emancipatórios de luta pela autonomia e integridade das formas de vida e aponta para a possibilidade de superação da antinomia clássica entre reforma ou revolução ao lançar nova luz à pluralidade de sentidos que a teoria crítica atribui hoje aos ideais emancipatórios (MELO, 2013, p. 42-43).

Tais pontos são caros a Benhabib, até porque dentro do debate interno ao feminismo, contrapondo-se a autoras vinculadas ao chamado pósestruturalismo, tentará desenvolver uma teoria comprometida com uma noção normativa de igualdade e uma noção fortemente intencional de autonomia. Andando de mãos dadas com isto, a autora não irá criticar de modo tão absoluto os ideais modernos e cosmopolitas - ao modo de outras teóricas próximas ao pós-estruturalismo - tão importantes ao liberalismo político e à tradição crítica, tanto é que desenvolverá a ideia de um universalismo interativo (BENHABIB, 2011, p. 1-20; 57-77). Não estruturado de modo abstrato, baseando-se em normas e imperativos necessários a uma pretensa paz perpétua e uma boa vida em qualquer situação histórica, e sim a partir de uma análise imanente de situações e contextos sócio-históricos específicos - bem como de possíveis reviravoltas e ressignificações de determinados símbolos, como é o caso dos véus na França (BENHABIB, 2011, p. 166184) - engendradoras de um conceito enriquecido de universalidade, essencial ao propósito de uma teoria crítica com pretensões emancipatórias e ligada às noções significativas para a modernidade, como liberdade e autonomia.

${ }^{10}$ Para mais, ver também: (HABERMAS, 2014a, p. 52-64). 
De par com esse projeto, nossa autora constitui também uma noção de sujeito, ou melhor, de um self narrativo (BENHABIB, 1999, p. 335-361), em que a contextualização seria importante, porém sem deixar de lado o potencial crítico da ação política feminista, de modo que a intencionalidade ainda deveria se fazer presente e não ser descartada. Um risco corrido, segundo nossa crítica, por autoras como Butler e sua concepção performática de sujeito (CYFER, 2015, p. 52) (Cf. GATENS, 2015). Seguindo as lições de Benhabib, via Cyfer principalmente, os sujeitos seriam construídos a partir de histórias, nas quais seriam tanto ouvintes como autores, lembrando que as redes de relações humanas e das histórias ali surgidas seriam a base sob a qual a vida se desenrolaria; todavia esses horizontes relacionais não seriam determinantes da subjetividade visto que, mesmo imersos nessas redes, as identidades seriam constituídas a partir do modo como se age diante delas. Destarte, os sujeitos não poderiam ser definidos a partir de um núcleo estável de significados dados antes do nascimento e sim pela capacidade de atribuírem significados à sua história e à sua capacidade de narrar. Contudo, essa capacidade é sempre exercida no contato intersubjetivo em um contexto em que já há vários significados socialmente válidos (CYFER, 2015, p. 53).

Em resumo, o self narrativo forjar-se-ia na própria ação, "entendida como um processo comunicativo que perdura durante toda a existência" (CYFER, 2015, p. 53), no qual os sujeitos serão narradores de suas histórias, contudo sem um domínio total sobre o presente e o futuro do sujeito em questão, visto que não serão as autoras exclusivas destas narrativas construídas em relações intersubjetivas onde os interlocutores interpretam a fala e tentam conciliar a história de vida apresentada, com a narração de sua própria história (CYFER, 2015, p. 54). Mesmo sabendo-se que ninguém é livre para inventar totalmente a si mesmo, porque narrativas afetam/são afetadas e condicionam/são condicionadas, isto abriria caminho para uma noção de autonomia mais acentuada que a de Mouffe e teóricas vinculadas ao pós-estruturalismo.

\section{Exercícios de leitura sobre Mouffe e Benhabib}

\section{Agonismo, cidadania radical e feminismo: Mouffe e a disputa por hegemonia}

De posse do que fora dito até aqui, agora nos concentraremos mais detidamente na crítica de Mouffe aos modelos deliberativos de democracia, principalmente aqueles expostos por Habermas/ Benhabib e Rawls/Cohen, com o fito de propor o seu modelo agonístico de democracia. Para a filósofa e cientista política belga, já nos idos da década de 2000, existiam óbvios e generalizados sinais de desapreço pelas atuais instituições democráticoliberais, assentados numa corrosão cada vez mais rápida da adesão popular aos antigos valores democráticos, o que, evidentemente, poderia abrir espaço para saídas de cunho autoritário e regressivo. Tendo isso em mente, Mouffe pretende avaliar as propostas oferecidas pelos teóricos contemporâneos para a resolução deste impasse coetâneo, principalmente em sua vertente conhecida como democracia deliberativa, a qual tomaria o processo de deliberação entre cidadãos livres e iguais como central para que se alcance decisões políticas em uma sociedade democrática.

Esse interesse pela deliberação teria como um de seus fins oferecer uma saída ao 'modelo minimalista' de democracia, oferecido por Joseph Schumpeter e Anthony Downs; modelo cujo fundamento estaria na crítica à inadequação do entendimento clássico de soberania popular em uma democracia de massas, de sorte que a democracia deveria passar a ser definida com um processo em que os indivíduos teriam a oportunidade de aceitar ou rejeitar seus líderes, pela via da competição eleitoral. Abandonando-se a natureza das discussões normativas sobre a democracia, em prol, pretensamente, do pluralismo não conciliável de interesses da modernidade. Em resposta a isto, John Rawls, em Uma teoria da justiça (1971), sugere que esse domínio do modelo agregativo encontrar-se-ia "na origem do atual desapreço a atingir as instituições democráticas, bem como da exuberância da 
crise de legitimidade das democracias ocidentais" (MOUFFE, 2005, p. 12). Com isso, Rawls reconhece o fato do pluralismo e, portanto, a necessidade de reconhecerem-se as diferentes concepções de bem, acreditando, porém, na possibilidade de se alcançar um consenso mais profundo, qualificado como moral e não só procedimental. É preciso notar, para a continuidade do argumento, que esse ponto de vista é partilhado pelos democratas deliberativos em geral, propugnando uma forma de racionalidade política normativa e a reconciliação das ideias de soberania democrática e defesa de instituições liberais. Oferecendo, assim, tanto uma base sólida de lealdade política, como a recuperação da dimensão moral da política, unindo, ao mesmo tempo, valores liberais e valores democráticos.

Rawls e Habermas afirmam a possibilidade de que procedimentos deliberativos adequados possam satisfazer tanto um critério de racionalidade, defendendo os direitos liberais, como a legitimidade democrática, defendendo soberania popular. Isso tudo a partir de um ideal de uma reinterpretação da soberania popular em termos intersubjetivos e procedimentais. Nessa tentativa de ligação forte entre democracia e liberalismo, tanto o alemão quanto o americano - além de Benhabib e Cohen, respectivamente -, ambicionavam forjar um liberalismo democrático responsável pela conciliação satisfatória entre igualdade e liberdade, de uma maneira que direitos democráticos, como os direitos individuais, ganhassem uma imbricação tal que um não poderia mais andar sem o outro. Um posicionamento compartilhado e que desemboca em uma "insistência comum na possibilidade de fundar autoridade e legitimidade em algumas formas de razão pública e sua crença compartilhada em uma forma de racionalidade que é não apenas instrumental, mas tem uma dimensão normativa: o 'razoável' para Rawls, a 'racionalidade comunicativa' para Habermas” (MOUFFE, 2005, p. 13).

Ou seja, ambos encontrariam o conteúdo idealizado da racionalidade prática nas instituições da democracia liberal, mesmo que divirjam na forma de elucidação desta razão: i) para Rawls, a ênfase deveria recair no papel desempenhado pela chamada posição original, em que os participantes deixam de lado todas as suas particularidades e interesses, exercendo a razão pública livre em um quadro de síntese entre uma concepção de justiça como equidade e elementos constitucionais essenciais; ii) já Habermas defende a chamada abordagem estritamente procedimental, na qual não haveria nenhum limite preestabelecido para a amplitude e o conteúdo da deliberação, sendo que os constrangimentos procedimentais mesmos da situação ideal de fala "que eliminarão as posições que não podem ser aceitas pelos participantes do ‘discurso' moral” (MOUFFE, 2005, p. 14). De um modo ou de outro, os democratas deliberativos tentariam, então, que colocar na ordem do dia o fato de que "nas condições modernas uma pluralidade de valores e interesses precisa ser reconhecida e que o consenso sobre o que Rawls chama de visões 'abrangentes' de natureza religiosa, moral e filosófica deve ser abandonada." Contudo, não levam isto às últimas consequências, dado que "não aceitam que isso leve à impossibilidade de um consenso racional sobre decisões políticas - entendendo-se por isso não um simples modus vivendi, mas um tipo moral de acordo, resultado do raciocínio moral livre entre iguais" (MOUFFE, 2005, p. 15).

Dando consecução ao argumento, ambos gostariam de fundamentar a adesão à democracia liberal como um tipo de acordo racional que fecharia as portas para a possibilidade de contestação, rifando o pluralismo para um domínio não público e isolando a política de suas consequências, tentando torná-la, sem sucesso, um terreno neutro e isolado do pluralismo de valores. Do mesmo modo, acabam privilegiando ou o termo da igualdade, ou termo da liberdade, ou da soberania popular, ou dos direitos individuais, o que leva Mouffe a crer que não são capazes de cumprir o que anunciavam e que gostariam de negar "o caráter paradoxal de democracia moderna e a tensão fundamental entre a lógica da democracia e a lógica do liberalismo" (MOUFFE, 2005, p. 16). Posto isto, é preciso reconhecer que ambas as autoras não conseguem reconhecer que autogoverno democrático e direitos individuais são constitutivos da democracia liberal, existindo 
uma tensão entre as duas 'gramáticas' respectivas, a qual nunca poderá ser eliminada. Isso não quer dizer que a democracia liberal seja inviável e sim que a possibilidade da existência de uma solução final para tal é impossível, de uma forma que os limites estabelecidos para o pluralismo passem a ser reconhecidos em sua natureza política e conflituosa, em lugar de apresentar estes limites como exigências da moralidade e da racionalidade.

Contra essas visões, Mouffe relembra algumas lições do filósofo político conservador Michael Oakeshott (1991), pois, para o autor, "a autoridade das instituições políticas não é uma questão de consentimento, mas de contínua adesão dos cives que reconhecem suas obrigações de obedecer às condições prescritas pela res publica" (MOUFFE, 2005, p. 17). Com isso em mente, a filósofa política diz que o essencial que escapa às autoras anteriores é que deve haver um conjunto de práticas que façam possível a criação de cidadãos democráticos, colocando em cena a centralidade de disponibilidade de formas democráticas de individualidade e subjetividade. Disponibilidade que escapa às autoras anteriores - agregativos ou deliberativos - por privilegiarem a racionalidade e deixarem de lado o papel crucial desempenhado por paixões e afetos na garantia da fidelidade a valores democráticos; isso anda junto com o fato de terem uma concepção de sujeito essencialista, anterior à sociedade e portador de direitos naturais, abstraindo-se relações sociais, de poder, linguagem, cultura e todo o conjunto de práticas que tornam a ação possível. Impedindo-se de se pensar as condições de existência de sujeitos democráticos, que só existirão e serão possíveis “com a multiplicação de instituições, discursos, forma de vida que fomentem a identificação com valores democráticos" (MOUFFE, 2005, p. 18).

Mouffe argumenta então que precisamos nos preocupar muito mais com os tipos de práticas e não as formas de argumentação, com o fito de constituir um modelo político alternativo e que impeça que mais pessoas sejam desprovidas da possibilidade de identificarem-se com concepções preciosas de cidadania e passem a identificações "que podem muito frequentemente colocar em risco o laço cívico que deveria unir a associação político-democrática" (MOUFFE, 2005, p. 18). De posse deste argumento, a filósofa lança mão, além de Oakeshott (1991) e sua linguagem de intercâmbio civil chamada res publica, do filósofo austríaco Ludwig Wittgenstein, o qual dá insights interessantes para se pensar uma crítica do racionalismo e a essencialização do sujeito, até porque "este último não pode ser fonte de significados linguísticos, uma vez que é através da participação em diferentes jogos de linguagem que o mundo nos é revelado" (MOUFFE, 2000, p. 104). Consequentemente, concordar com a definição de um termo não seria suficiente e é preciso haver um acordo sobre o modo com que o utilizamos, de sorte que os procedimentos passam a ser tomados como um conjunto de práticas, envolvendo compromissos éticos substanciais e que nunca podem ser neutros, constituindo - se não só em uma simples crença e sim um modo de avaliar-se uma vida. $\mathrm{O}$ que, necessariamente, traz à baila o reconhecimento dos limites do consenso.

Esse movimento argumentativo permite que o pluralismo seja levado a sério, abrindo-se mão de um consenso racional eternizado e que levaria a pensar que poder-se-ia escapar das formas de vida humanas e dos antagonismos a ela correspondentes. Nesse bojo, a autora forja outro movimento interessante, a saber: a consideração do poder como constitutivo das relações sociais, jogando luz sobre o caráter inerradicável do antagonismo em meio a estas relações, decorrente, justamente, do pluralismo de valores. Retomando as críticas ao pensamento liberal, efetuadas pelo teórico conservador Carl Schmitt (SCHMITT, 2009) (MOUFFE, 2000 , p. 137-179), argumenta que o pensamento liberal acaba desviando do político e acaba indo para a ética e a economia, no caso dos democratas liberais recorria-se à primeira. Contra isto, Mouffe propõe uma abordagem a qual possa tomar como central a questão do poder e do antagonismo, de uma forma que aí pode-se vislumbrar uma relação entre poder, legitimidade e ordem hegemônica, sistematicamente negada pelo racionalismo 
exacerbado das teorias deliberativas em que a legitimidade é fundada na racionalidade pura.

Contudo, para que isso ocorra é preciso ter em mente uma distinção essencial efetuada pela autora, entre o político e a política, o primeiro como dimensão do antagonismo inerente às relações humanas, proteiforme e com grande potencial emergente em diferentes tipos de relações sociais e a segunda como complexo de instituições, discursos e práticas que almeja à certa ordem e à organização da existência humana, porém sem perder seu caráter conflitivo. Compreendendo esta divisão e a tentativa da política domesticar os conflitos inerentes ao político, como seus antagonismos, é que se chegaria à questão central da política democrática, qual seja: "a criação da unidade em um contexto de conflitos e diversidade; está sempre ligada à criação de um 'nós' em oposição a um 'eles", sendo que a "novidade da política democrática não é a superação dessa oposição nós - eles - que é uma impossibilidade -, mas o caminho diferente em que ela é estabelecida. O ponto crucial é estabelecer essa discriminação nós - eles de um modo compatível com a democracia" (MOUFFE, 2005, p. 20). Portanto, em uma democracia o 'eles' deve ser constituído não como o inimigo a ser destruído e sim como o adversário, com ideias que deveriam ser combatidas. Adversário este com quem manteríamos uma base comum, pois aderiríamos a princípios éticos comuns em uma democracia liberal: liberdade e igualdade.

Essa discordância não pode, contudo, ser resolvida pela via da deliberação e do discurso racional, dado o pluralismo radical de valores, mesmo assim pactos não poderiam ser jogados fora, fazendo parte cotidiana da política, "mas deveriam ser vistos como interrupções temporárias de uma confrontação contínua" (MOUFFE, 2005, p. 20). Com a introdução da categoria de adversário há a requisição para tornar complexa a noção de antagonismo, agora dividido em duas frentes: i) antagonismo - representando uma luta entre inimigos - e ii) agonismo - representando uma luta entre adversários. Desta forma, Mouffe consegue reformular o problema "dizendo que, desde a perspectiva do 'pluralismo agonístico', o propósito da política democrática é transformar antagonismo em agonismo" (MOUFFE, 2005, p. 21). Demandando canais a partir dos quais as paixões coletivas poderão se expressar sobre questões, que constituirão o opositor como adversário e não como inimigo.

Destarte, as paixões seriam mobilizadas em prol de desígnios democráticos e a confrontação agonística passa a ser a condição de existência da democracia, por meio do reconhecimento e da legitimação dos conflitos; nesse sentido, o volume de consenso exigido por uma democracia pluralista está fadado a ser um 'consenso conflituoso', "como resultado temporário de uma hegemonia provisória, como estabilização do poder e que ele acarreta alguma forma de exclusão" (MOUFFE, 2005 , p. 21). É claro que tais confrontações, idealmente falando, se dariam em torno das diversas concepções de cidadania que correspondem às diferentes interpretações dos princípios éticopolíticos: liberal-conservadora, social-democrata, neoliberal, radical-democrática e assim por diante. Cada uma delas propõe a sua própria interpretação do 'bem comum' e tenta implementar uma forma diferente de hegemonia. Em suma, esse modelo agonístico de democracia, ao permitir o claro dissenso e promover instituições em que possa ser manifestado, segundo a teórica belga, abre espaço para uma democracia pluralista pujante, deixando de lado a 'utopia' deliberativa de uma sociedade bem-ordenada, por conseguinte, sem conflitos.

De todo modo, o que isso teria a ver diretamente com a política, principalmente com a questão do poder, no feminismo? Entroncando na discussão feita anteriormente sobre a crítica ao essencialismo, a nossa teórica belga argumenta que a entificação operada por algumas correntes do feminismo, da mulher ou de alguns de seus atributos, mostra-se politicamente muito insuficiente, principalmente se tivermos em vista a construção de uma política alternativa democrática e uma cidadania radical, cujo objetivo seria a articulação das lutas ligadas às diferentes formas de opressão e subordinação. Nessa lógica, feministas empenhadas 
em uma política democrática e radical deveriam operar uma desconstrução das identidades essenciais, porquanto isto seria essencial para melhor compreensão da diversidade de relações sociais a que os princípios de igualdade e liberdade devem ser aplicados. Dessa maneira, apenas quando se afasta de uma concepção do sujeito como agente, ao mesmo tempo, transparente para si e racional e de uma visão monolítica do aglomerado das relações de sujeição e subordinação, pode-se ver que um mesmo indivíduo pode ser, a um só tempo, dominante em uma relação e subordinado em outra. Isto é,

podemos conceber o agente social como sendo constituído por um conjunto de 'posições de sujeito', que nunca podem ser totalmente fixas num sistema fechado de diferenças, composto por uma diversidade de discursos, entre os quais não existe uma relação necessária, mas antes um constante movimento de sobre determinação e deslocamento (MOUFFE, 2000, p. 104-105).

Seguindo o argumento, para ser constituído de maneira adequada, esse projeto exige o afastamento da ideia essencialista de uma identidade das mulheres enquanto mulheres, além de evitar a tentativa de constituir uma política exclusivamente feminista. Essa postura tem o intuito de colocar na ordem do dia uma política feminista, em que a busca de suas metas e objetivos - no caso, a mudança radical de todos os discursos e práticas, constitutivos da categoria mulher, com o fito de subordiná-las deva ser entendida no contexto de uma articulação complexa de exigências distintas. Não obstante, a autora lembra que é preciso ter consciência do fato de que os objetivos dentro do feminismo podem ser diferentes, com vários discursos em que podem ser enquadrados (marxista, liberal, democrático radical etc), de uma maneira que a criação de um único e verdadeiro feminismo séria estéril, interditando a maior contribuição do feminismo à política, a saber: a sua contribuição a partir de uma reflexão sobre as condições de criação de uma igualdade real entre as mulheres. Expandindo, assim, a contribuição sobre a compreensão das diferentes formas de subordinação das mulheres.
Por conseguinte, para as feministas empenhadas em lutar contra as mais diversas formas de subordinação, para além da subalternização via gênero, é de suma importância que se lance mão de uma abordagem que permita compreender como o sujeito é construído por meio dos discursos e das posições várias ocupadas por ele. Constituindo-se como uma posição muito mais adequada, principalmente se comparada com aquelas que reduzem nossa identidade a uma única posição, seja de classe, gênero ou raça. Até porque o projeto democrático proposto pela autora belga fica melhor servido caso a perspectiva adotada permita entender as diversas formas nas quais as relações de poder são construídas, possibilitando a descoberta das formas de exclusão presentes em pretensões universalistas e nas vozes dos que vindicam terem encontrado a verdadeira essência da racionalidade. É justamente "por isso que a crítica do essencialismo e todas as formas que assume - humanismo, racionalismo e universalismo - longe de constituir um obstáculo à formulação de um projeto democrático feminista, é, na realidade, uma verdadeira condição de sua possibilidade" (MOUFFE, 2000, p. 120).

\section{Ética discursiva, teoria normativa e feminismo:} Benhabib e a esfera pública

É forçoso notar que mesmo Benhabib tendo acompanhado passos importantes da sedimentação teórica de Habermas, principalmente referentes à esfera pública e à circulação de outros sentidos de emancipação não mais animados pelo paradigma produtivista, a filósofa constrói pontos importantes de crítica e de diferenciação frente ao filósofo alemão, fiquemos com apenas dois, os quais acreditamos ser essenciais. O primeiro momento de diferenciação entronca-se em um debate bastante caro ao feminismo, visto que a autora critica um estabelecimento por demais estanque do que é privado e do que é público na noção habermasiana de esfera pública e propõe um deslocamento de seus pressupostos (BENHABIB, 2007a, p. 107-113). Isto porque historicamente as mulheres foram sistematicamente relegadas à 'esfera privada', cuja 
estrutura baseia-se em três dimensões: a intimidade, a consciência religiosa e moral e os direitos mínimos das liberdades econômicas (BENHABIB, 2007a, p. 108-109). Logo, as questões e demandas sociais, econômicas e políticas trazidas pelas mulheres, não eram tidas como políticas e dignas de adentrar as esferas públicas, levando a contínuas inviabilizações de suas reivindicações por justiça e pela publicização e discussão dos temas coletivamente tidos como relevantes a elas (MELO, 2015).

Isto posto, Benhabib argumenta que a linha demarcatória entre o que é considerado público e privado deve sempre entrar em negociação, tendo aí um importante papel do movimento autônomo e organizado das mulheres, detentor de um importante impulso civilizador na remarcação/renegociação constante destas duas esferas. Ainda nesse mesmo diapasão, a nossa filósofa considera importante haver também um reajustamento democrático, passando pelo crivo do debate público, daquilo que é considerado com uma 'boa vida' e dos temas de justiça, levando-nos ao segundo ponto de diferenciação com Habermas. Dado que, se este considerava a esfera pública um espaço social, devendo ser visto sob os olhos da sociologia e da história (HABERMAS, 2014a), Benhabib, unindo-a ao que chama de ética do discurso, passará a pensála como um modelo dotado de normatividade, mas que teria o dever de levar em conta os indivíduos com histórias e identidades outras concretas, dotados de uma constituição afetiva e emocional distinta; censurando, deste modo, um racionalismo exacerbado em Habermas (MELO, 2015, p. 21) ${ }^{11}$.

Seguindo o argumento, a filósofa propõe um modelo deliberativo de democracia, no qual as suas pretensões de validade devem necessariamente estar fundadas em um modelo da ética do discurso, posto que este conseguiria propiciar as condições necessárias a uma deliberação coletiva e igualitária entre os cidadãos. Mas como efetivaria isto? Para Benhabib, a ideia básica desse modelo ético é de que só seriam consideradas válidas aquelas normas que poderiam receber a anuência de todos aqueles possíveis atingidos por seus efeitos. Resultando de uma deliberação com as características seguintes: a) a participação deliberativa deve ser guiada por normas de simetria e igualdade, abrindo espaço para todos falarem e questionarem; b) todos têm o direito de questionar todos os tópicos fixados na discussão; c) todos poderão introduzir questionamentos e reflexões sobre as regras utilizadas no procedimento discursivo, além do modo que sua execução deve se dar (BENHABIB, 2007b, p. 51). Dito isto, o critério de inclusão do outro - concreto, como colocado anteriormente - é radicalmente pautado por nossa teórica, a partir de uma vinculação estreita "entre os fundamentos normativos da legitimidade democrática com uma teoria moral universal baseada no modelo discursivo de validade [...]" (BENHABIB, 2007b, p. 52), afastando-se claramente de Mouffe e seu agonismo.

Segundo esse modelo deliberativo, os seus procedimentos mesmos gerariam sua legitimidade interna, assegurando, ainda por cima, certo grau de racionalidade prática decisória, já que nenhum indivíduo sozinho pode antecipar toda a variedade de perspectivas em conflito, como também não pode deter todas as informações necessárias e consideradas relevantes ao processo. Nesse bojo, em meio ao processo deliberativo, os indivíduos tomariam contato com os diversos conflitos e perspectivas ali colocados, situando as preferências e opiniões individuais em um nível muito mais alto de reflexividade, pois ao apresentar os seus pontos de vista e posições aos outros indivíduos, devem justificálos via articulação de boas razões em um contexto público e nessa articulação vê-se forçado "a pensar sobre o que seria uma boa razão para todos os outros envolvidos. Desse modo, o indivíduo é forçado a pensar a partir do ponto de vista de todos os envolvidos, a quem 'suplica' o consentimento" (BENHABIB, 2007b, p. 54). Adotando, desta

${ }^{11}$ Benhabib (2007a, p. 113) chega mesmo a propor que as feministas não deveriam apenas criticar Habermas, mas sim fazer uma aliança dialética com o filósofo alemão e sua teorização, já que abriria a possibilidade de se pensar a inclusividade e a acessibilidade ao debate público dos Outros concretos diferentes. 
forma, um ponto de vista do que Arendt chamaria de mentalidade ampliada.

Esta concepção procedimentalista do fazer democrático conta ainda com três pontos adicionais importantes para nossa autora: i) há uma pressuposição forte de uma sociedade assentada em um pluralismo de valores e pontos de vista, constituindo-se como um passo importante para a racionalidade proposta encontrar formulações razoáveis do bem comum, sendo o pluralismo buscado no nível procedimental e não das convicções substantivas; ii) outro ponto de partida relevante é o fato de que para além dos conflitos de valores e de interesses sociais, a vida social também necessita de cooperação entre os indivíduos, tanto é que os procedimentos devem convencer que as condições de cooperação são legítimas e que tais procedimentos podem servir como peneiras ponderadoras dos interesses conflitantes; iii) qualquer sociedade moderna não pode organizar suas questões com a ficção de uma assembleia de massas realizando deliberações em público e coletivamente; no lugar disto, Benhabib pensa em uma miríade de modos de associação individuais em que todos os concernidos e atingidos - dentre eles, as mulheres e as demandas feministas - pela política podem articular seus pontos de vista. É pela via destas associações e redes que uma comunicação anônima pode surgir e para o modelo deliberativo em questão "é fundamental que se privilegie essa esfera pública de redes justapostas e mutuamente entrelaçadas, e as associações de deliberação, contestação e argumentação" (BENHABIB, 2007b, p. 58).

Desta feita, contrariamente às desconfianças de teóricas feministas frente a este modelo, como as trazidas por Young e Fraser, de que seria um modelo machista e racionalista, com um discurso hegemônico em que isto transparece e desconsiderador das emoções e da multiplicidade de vozes e suas articulações públicas (BENHABIB, 2007b, p. 59), Benhabib responde argumentando que as críticas ali feitas pecariam por um inespecificidade patente. Inespecíficas, porque confundiriam a crítica aos pressupostos institucionais - de fato, muitas vezes problemáticos em um sentido feminista - e os pressupostos normativos. Pressupostos, segundo a nossa teórica, fundamentais para a inclusão radical de todos os concernidos, inclusive e principalmente para as mulheres e para as reivindicações históricas do feminismo, mantendo um ideal moral de imparcialidade, norteador de articulações e deliberações públicas, essenciais à inclusividade radical e à possibilidade de expressão da heterogeneidade, alteridade e diferença. Forjando, deste modo, uma conformação política importante às políticas feministas, podendo trazer à tona, por exemplo, a já discutida questão da divisão estanque entre o público e o privado, fiadora de relações de opressão seculares.

A teórica feminista chega mesmo a apontar afinidades eletivas das mais interessantes entre a ética do discurso e o movimento feminista, em razão de, grosso modo, ambos considerarem essenciais as relações de igualdade recíproca, baseadas no respeito mútuo entre as partes envolvidas, visando a negociação discursiva de normas sociais, a apropriação flexível da tradição, bem como na formação de identidades reflexivas e fluidas, ligando-se ao já explorado self narrativo (BENHABIB, 2007a, p. 110-112). Disto isto, Benhabib, como Mouffe, mesmo que trilhando caminhos distintos, lança mão de um projeto crítico e democrático, em que a crítica e os movimentos feministas assumem uma figura de proa e propiciam uma alternativa às saídas autoritárias e às estruturas de assujeitamento e opressão das sociedades modernas, especialmente ao machismo patriarcal.

\section{Considerações finais}

Tendo em vista aquilo que fora até aqui exposto, é importante notar que há um conjunto de diferenças substantivas entre as autoras aqui mobilizadas, podendo ser assim colocadas. Os referenciais teóricos de ambas são, no geral, bastante distintos, tendo Mouffe desenvolvido suas formulações utilizando-se de um arcabouço vasto indo de Marx a Gramsci e Derrida, mas que, ao fim e ao cabo, entronca em posições caras ao pósestruturalismo, como quando lança mão de uma 
concepção de sujeito travejada, fortemente, por relação de poder e discursivas - aproximando-se de uma autora como Butler. Forjando, aos olhos de Benhabib, uma concepção de sujeito sobredeterminado pelo contexto, algo que traria à baila uma noção diminuta de autonomia e ação política.

No caso de Benhabib, as críticas feitas a uma concepção universalista e abstrata de sujeito são levadas a sério e, de certa forma, aproveitadas em sua concepção de self narrativo - acima explorado -, porém, por pertencer a uma tradição da teoria crítica em que tanto um padrão normativo de igualdade e uma noção forte de autonomia transparecem, teve de se utilizar de uma conceituação que abarcasse tanto a contextualização do sujeito, quanto a sua capacidade de transformar o contexto. Algo que, aos olhos da teorização pós-estruturalista, poderia trazer certa metafisica universalista.

Quanto à política e sua feitura, Mouffe apostaria em uma noção agonística de democracia, cuja construção poderia abarcar de modo mais satisfatório a pluralidade de interesses inerente às sociedades modernas e contemporâneas. Destarte, a especificidade das relações políticas - sem perder de vista o lugar ocupado pelo político e pela política - não seria deixada de lado em prol de uma valorização da moral - feita, segundo Mouffe pelos democratas deliberativos, à maneira da própria Benhabib -, responsável, em última instância, pela expulsão desta mesma pluralidade de interesses da sociedade política em geral. Já Benhabib, ao defender um modelo deliberativo de democracia - cujas pretensões de validade devem ser forjadas tendo em vista uma ética do discurso essencialmente inclusiva, além de uma legitimidade engendrada a partir de procedimentos deliberativos determinados -, intentaria defender o máximo possível a pluralidade de interesses próprios da modernidade. Porém, ao invés de apostar em uma 'vocação' agonística das relações políticas, encaminhou para a ordem do dia uma noção do fazer político em que condições de cooperação recíproca fossem valorizadas e peneirassem os mais diversos interesses conflitantes. Caso contrário, sem essa articulação de conflitos de interesses, não haveria a possibilidade de uma cooperação social democrática aceitável para os mais diversos setores da sociedade, abrindo espaço para uma não inclusão e fechando o caminho para os mais diversos modos de associações, essenciais à democracia.

Sendo assim, apesar das distinções importantes tanto entre as concepções do político e do fazer político, como também das suas concepções de sujeito - com colocações distintas sobre a autonomia e seu lugar, ligando-se a um debate tão significativo ao feminismo em geral (ALLEN, 2007) - há algumas aproximações importantes, as quais serão rapidamente desdobradas dos exercícios de leitura acima expostos, mas que mereceriam uma pesquisa mais pormenorizada, é claro. Em primeiro lugar, ambas as autoras não aceitam como pressuposto as diferentes noções de sujeito em circulação nas teorias políticas, noções que escondem uma visão masculina sobre as identidades e indivíduos, inviabilizando as demandas políticas historicamente constituídas pelas mulheres em seus diferentes nichos de opressão e subalternidade. As duas teóricas, de diferentes maneiras, levam em conta os contextos, em sentido amplo, em que estão inseridas, preocupando-se com a possibilidade de uma ação política contrária às opressões e explorações. Em segundo lugar, uma e outra, embora com compreensões distintas, apostam em uma visão radicalmente democrática do fazer político -, visando a conformação de uma sociedade eminentemente democrática e de fato pluralista, contra tendências autoritárias e/ou de constituição de uma servidão voluntária sem participação, presentes na contemporaneidade. Tudo isso com o fito de oferecer alternativas de oposição também às diferentes formas de arbitrariedade e sujeição, principalmente frente ao machismo e às estruturações patriarcais.

Faremos, agora, um breve exercício de indicação das potencialidades e limites das estratégias e abordagens até aqui trabalhadas.

Ao nosso ver, dentro de uma voga consensualista a respeito da democracia e da política (representada, de formas distintas, por Rawls, Habermas, Cohen e Benhabib), na qual a política 
deveria ser domesticada por valores morais que conseguiriam estancar o seu fluxo e os conflitos a ela inerentes, Mouffe traz de volta à baila um elemento central do político, a saber: o conflito e o agonismo. Todavia, concordamos com Luís Felipe Miguel (2014) quando este argumenta que, apesar deste elemento louvável, Mouffe recai, ao distinguir entre um antagonismo disruptivo (ruim) e um agonismo (bom para a democracia), na mesma ilusão consensualista de poder domar o político por meio de consensos morais abstratos prévios. Até porque, como bem pontua Miguel (2014, p. 33), “o consenso quanto aos valores básicos está sujeito às mesmas formas de manipulação e de produção de preferências adaptativas, comuns às interações entre desiguais, que afetam outras modalidades de consenso".

Benhabib, conforme vimos, tentará forjar esquemas valorativos fundados em um modelo da ética do discurso, a partir do qual se conseguiria propiciar as condições necessárias a uma deliberação coletiva e igualitária entre os cidadãos. Apesar de pretender com um modelo deliberativo forjar uma política que se pretende aberta e igualitária, o modelo de Benhabib padece do mesmo problema político de outras teorizações normativas e neokantianas: a tentativa de deter abstratamente o fluxo da política, tentando fixar seus processos e dinâmicas em termos morais fundantes (SKINNER, 2002) ${ }^{12}$. Desta feita, a compressão do político por parte de Benhabib, apesar de intenções esclarecidas, careceria de imanência e materialidade.

Outro elemento decisivo, ao nosso ver e a partir do estado da arte das teorias feministas contemporâneas, que limitaria as análises de Mouffe e Benhabib, diz respeito ao fato de pouco olharem para os processos materiais de produção e reprodução da sociedade, principalmente ao papel subalterno atribuído nestes processos às mulheres. De forma mais específica: Mouffe e Benhabib, ao deixarem de lado aspectos materiais decisivos do andamento das sociedades capitalistas, obscurecem elementos decisivos para subjugação e dominação das mulheres. Esse processo de dominação se daria, segundo Federici (2017), por variados mecanismos capitalistas e patriarcais, os quais, desde os primórdios da acumulação primitiva, teriam, sistematicamente, expulsado as mulheres do público e as colocado na esfera privada de modo que fossem responsáveis pela reprodução social não-remunerada da vida das pessoas em geral e a da classe trabalhadora em particular (BHATTACHARYA, 2019), configurando uma forma de dominação econômica e política que restringe a autonomia e subjuga amplas camadas de mulheres, principalmente as mulheres que não pertencem ao Norte Global e às camadas sociais mais ricas. Fortalecendo, além do patriarcalismo e das divisões de classe, o colonialismo e o racismo (ARRUZA; BHATTACHARYA; FRASER, 2019).

À vista disso, pode-se notar que, ao enfrentarem questões centrais ao debate feminista mais geral, qual seja, as da autonomia, do poder político e suas relações com o feminismo, Mouffe e Benhabib, apesar de diferenças nos seus pressupostos, lineamentos argumentativos e influências teórico-políticas, podem chegar a similitudes interessantes. Além de um ponto de fuga em comum assentado na tentativa de se opor a uma ordenação patriarcal e pouco inclusiva em relação aos diversos valores encarnados nos indivíduos, Mouffe e Benhabib, de formas distintas, veriam como decisiva a construção de determinados consensos normativos, morais e/ou valorativos a partir dos quais o dissenso e o consenso político e democrático poderiam se dar.

Atualmente, Mouffe (2019) aposta num populismo de esquerda que, num período de crise da hegemonia neoliberal, levaria a bom termo uma estratégia discursiva de construção de uma

${ }^{12}$ Ao nosso ver, a tentativa de Benhabib (2020) em defender teorias neokantianas da crítica de serem apolíticas falha ao deixar de lado algo essencial: o caráter conflituoso e contingente do político. Na verdade, a estratégia argumentativa da autora é dizer que está preocupada com direitos humanos e com a dignidade política, por isso busca construções morais consensuais. Afora a tentativa de construção retórica de uma posição política razoável contra oponentes supostamente inconsequentes frente à cidadania, Benhabib é superficial ao tratar a dinâmica imanente do político. 
fronteira entre o "nós", o "povo" e a oligarquia neoliberal e, com isto, aprofundaria a democracia. Benhabib (2020), por sua vez, argumenta que o modelo populista, à esquerda ou à direita, deslizaria facilmente para xenofobia, nacionalismo, nativismo e autoritarismo, de modo que o essencial para a democracia seria defender a "pluralização dos espaços de luta democrática para colocar as lutas transnacionais bem como locais e regionais em conjunto com as nacionais" (BENHABIB, 2020, p. 5). Em nossa leitura, apesar das diferenças, há, em última instância, no pensamento das duas autoras, um apagamento relativo da dimensão radicalmente contingente da política e do caráter estrutural das dominações materiais no capitalismo global.

\section{Referências}

ADORNO, T. W. Contribución a la doctrina de las ideologias. In: ADORNO, T. W. Escritos sociológicos I: obra completa 8. Madrid: Akal, 2004. p. 427-447.

ADORNO, T. W. Aspectos. In: ADORNO, T. W. Três estudos sobre Hegel. São Paulo: Ed. Unesp, 2013. p. 124.

ALLEN, A. The politics of ouservels: power, autonomy and gender in contemporany critical theory. New York: Columbia University, 2007.

ALVES, A. R. C. O conceito de hegemonia. Lua Nova, São Paulo, v. 2, n. 80, p. 71-96, 2010.

ARATO, A; COHEN, J. Civil society and political theory. Massachusetts: MIT Press, 1992.

ARRUZA, C.; BHATTACHARYA, T.; FRASER, N. Feminismos para os 99\%: um manifesto. São Paulo: Boitempo, 2019.

AVRITZER, L. Teoria crítica e teoria democrática. Novos Estudos CEBRAP, São Paulo, n. 53, 167188, 1999.

BHATTACHARYA, T. O que é a teoria da reprodução social? Revista Outubro, São Paulo, v. 1, n. 32, p. 100-113, 2019.
BENHABIB, S. Breves reflexões sobre o populismo (de esquerda ou de direita).Dissonância: Revista de Teoria Crítica, Campinas, v. 3, n. 1, p. 1-13, 2020.

BENHABIB, S. Dignity in adversity: human rights in turbulent times. Cambridge: Polity Press, 2011.

BENHABIB, S. Sexual difference and collective identities: the new global constellation. Signs: Jornal of Women in Culture and Society, Chicago, v. 24, n. 2, p. 335-361, 1999.

BENHABIB, S. Situating the self: gender, community and postmodernism in contemporany ethics. Cambridge: Polity Press, 2007a.

BENHABIB, S. Sobre um modelo deliberativo de legitimidade democrática. In: WERLE, D. L.; MELO, R. (org.). Democracia deliberativa. São Paulo: Singular; Esfera Pública, 2007b. p. 47-79.

BUTLER, J. Problemas de gênero: feminismo e subversão da identidade. Rio de Janeiro: Civilização Brasileira, 2003.

BUTLER, J. The Psychic Life of Power: theories in subjection. Stanford: Stanford University Press, 1997.

CYFER, I. Afinal, o que é uma mulher? Simone de Beauvoir e 'a questão do sujeito' na teoria crítica feminista. Lua Nova, São Paulo, n. 94, p. 41-77, 2015.

DERRIDA, J. A escritura e a diferença. São Paulo: Perspectiva, 1995.

ENGELS, F. Fenomenologia do espirito. São Paulo: Boitempo, 2012.

MARX, K.; ENGELS, F. A ideologia alemã. São Paulo: Boitempo, 2009.

MARX, K.; ENGELS, F. Manifesto Comunista. São Paulo: Boitempo, 2010.

FEDERICI, S. Calibã e a bruxa: mulheres, corpo e acumulação primitiva. São Paulo: Ed. Elefante, 2017.

FOUCAULT, M. Microfisica do poder. Rio de Janeiro: Graal, 2012.

GATENS, M. Let's talk story: gender and the narrative self. Critical Horizons, London, n. 1, v. 15, p. 40-51, 2015. 
GRAMSCI, A. Cadernos do Cárcere. Rio de Janeiro: Civilização Brasileira, 2014a. v. 3, 5.

HABERMAS, J. A nova obscuridade. In: HABERMAS, J. A nova obscuridade: pequenos escritos políticos V. São Paulo: Editora Unesp. 2015. p. 207-239.

HABERMAS, J. Consideração final: de Parsons a Marx, pela mediação de Weber. In: HABERMAS, J. Teoria do agir comunicativo: sobre a crítica da razão funcionalista. São Paulo: Ed. WMF Martins Fontes, 2012. v. 2, p. 543-729.

HABERMAS, J. Prefácio à nova edição (1990). In: HABERMAS, J. Mudança estrutural da esfera pública: investigações sobre uma categoria da sociedade burguesa. São Paulo: Ed. Unesp, 2014. p. 35-89.

HEGEL, G. W. F. Fenomenologia do Espírito. Petrópolis: Vozes, 2012.

HORKHEIMER, Max. A Presente Situação da Filosofia Social e as Tarefas de um Instituto de Pesquisas Sociais. Revista Praga, São Paulo, n. 7 , p. 121-132, 1999.

HORKHEIMER, M. Teoria tradicional e teoria crítica. In: HORKHEIMER, M.; ADORNO, T. Textos Escolhidos. São Paulo: Abril Cultural, 1983. p. 31-68.

JAY, M. A imaginação dialética: história da Escola de Frankfurt e do Instituto de Pesquisas Sociais, 1923-1950. Rio de Janeiro: Contraponto, 2008.

KANT, I. Resposta à pergunta: o que é esclarecimento?. In: KANT, I. O que é o esclarecimento? Rio de Janeiro: Via Verita, 2011. p. 23-37.

LACAN, J. O estádio do espelho como formador da função do eu. In: LACAN, J. Escritos. Rio de Janeiro: Jorge Zahar, 1998. p. 96-104.

LAClAU, E.; MOUFFE, C. Hegemony and Socialist strategy. Londres: Verso Books, 2001.

LENIN, V. I. O Estado e a revolução: o que ensina o marxismo sobre o Estado e o papel do proletariado na Revolução. São Paulo: Expressão Popular, 2010.

MELO, R. Marx e Habermas: teoria crítica e os sentidos da emancipação. São Paulo: Saraiva, 2013.
MELO, R. Repensando a esfera pública: esboço de uma teoria crítica da democracia. Lua Nova, São Paulo, n. 94, p. 11-39, 2015.

MELLUCCI, A. The symbolic challeng of contemporany movements. Social Research, New York, n. 52, p. $789-816,1985$.

MIGUEL, L. F. Democracia e representação: territórios em disputa. São Paulo: Ed. Unesp, 2014.

MOUFFE, C. O regresso do político: trajectos. Lisboa: Gradiva, 2000.

MOUFFE, C. Por um modelo agonístico de democracia. Revista de Sociologia e Política, Curitiba, n. 25, p. 11-23, nov. 2005.

MOUFFE, C. Por um populismo de esquerda. São Paulo: Autonomia Literária, 2019.

NOBRE, M. A teoria crítica. Rio de Janeiro: Zahar, 2004.

NOBRE, M. Fecho. In: NOBRE, M. A dialética negativa de Theodor W. Adorno: a ontologia do estado falso. São Paulo: Iluminuras, 1998. p. 179187.

NOBRE, M. Introdução: modelos de teoria crítica. In: NOBRE, M. Curso livre de teoria crítica. Campinas: Papirus, 2015. p. 9-21.

NOBRE, M. Prefácio. In: MELO, R. Marx e Habermas: teoria crítica e os sentidos da emancipação. São Paulo: Saraiva, 2013. p. 13-23.

OAKESHOTT, M. On being conservative. In: OAKESHOTT, M. Rationalism in politics and other essays. $2^{\text {nd }}$ ed. Indianapolis: Liberty Fund, 1991. p. 407-437. Disponível em: http://www.geocities. com/Heartland/4887/conservative.html. Acesso em: 20 maio 2020.

POLLOCK, F. State Capitalism: its possibilities and limitations. In: ARATO, A.; GEBHART, E. The Essential Frankfurt reader. New York: Urizen Books, 1985. p. 71- 95.

RICUPERO, B. Caio Prado Jr. e a nacionalização do marxismo no Brasil. São Paulo: Ed. 34, 2000.

RUGITSKY, F. Friedrich Pollock: limites e possibilidades. In: NOBRE, M. (org.). Curso livre de teoria crítica. Campinas: Papirus, 2015. p. 53-73. 
SCHMITT, Carl. O conceito do político: teoria do partisan. Belo Horizonte: Del Rey Editora, 2009.

SKINNER, Q. Retrospect: studying rhetoric and conceptual change. In: SKINNER, Q. Vision of Politics: regarding method. Cambridge: Cambridge University Press, 2002. v. 1, p. 175-188. 